\title{
Inhibitory effect of Salvia plebeia leaf extract on ultraviolet-induced photoaging-associated ion channels and enzymes
}

\author{
YOU-JIN CHANG ${ }^{1 *}$, DONG-UNG LEE ${ }^{2 *}$, DA YEONG NAM ${ }^{2}$, SUNG MIN CHO $^{3}$, \\ SEUNGUG HONG ${ }^{3}$, JOO HYUN NAM ${ }^{4,5}$ and WOO KYUNG KIM ${ }^{5,6}$
}

${ }^{1}$ Department of Korean Medical Ophthalmology, Otolaryngology and Dermatology, Dongguk University College of Korean
Medicine, Goyang 410-773; ${ }^{2}$ Division of Bioscience, Dongguk University, Gyeongju 780-714;
${ }^{3}$ Department of Pediatrics, Dongguk University Ilsan Hospital, Goyang 410-773;
${ }^{4}$ Department of Physiology, Dongguk University College of Medicine, Gyeongju 780-714;
${ }^{5}$ Channelopathy Research Center (CRC), Dongguk University College of Medicine;
${ }^{6}$ Department of Internal Medicine, Graduate School of Medicine, Dongguk University, Goyang 410-773, Republic of Korea

Received August 17, 2015; Accepted October 19, 2016

DOI: $10.3892 /$ etm.2017.4025

\begin{abstract}
In traditional Korean/Asian medicine, Salvia plebeia R.Br. (S. plebeia) leaves are used to treat inflammatory diseases, including dermatitis, cough, asthma and toothache. Recently, S. plebeia leaves have been applied in skin care, as they promote skin lightening and elasticity. Therefore, the present study investigated the anti-aging effects of $S$. plebeia leaf methanolic extract and its fractions (dichloromethane, ethylacetate and n-butanol). The results of a whole-cell patch clamp analysis indicated that the methanolic extract mediated ultraviolet (UV)-induced photoaging-associated ion channels, transient receptor potential vanilloid 1 (TRPV1) and calcium
\end{abstract}

Correspondence to: Dr Woo Kyung Kim, Department of Internal Medicine, Graduate School of Medicine, Dongguk University, 27 Dongguk-ro, Ilsan Dong-gu, Goyang 410-773, Republic of Korea E-mail:wk2kim@naver.com

Dr Joo Hyun Nam, Department of Physiology, Dongguk University College of Medicine, 123 Dongdae-ro, Gyeongju 780-714, Republic of Korea

E-mail: jhnam@dongguk.ac.kr

*Contributed equally

Abbreviations: TRPV1, transient receptor potential vanilloid 1; ORAI1, calcium release-activated calcium channel protein 1; AP-1, activate the nuclear activator protein; MMPs, metalloproteinases; MMP-1, collagenase; MMP-9, gelatinase B; ET, endothelin; STIM, stromal interaction molecule; ER, endoplasmic reticulum; $\mathrm{PKC}$, calcium-dependent protein kinase $\mathrm{C}$

Key words: Salvia plebeia, transient receptor potential vanilloid 1, calcium release-activated calcium channel protein 1 , tyrosinase activity, elastase activity, ultraviolet-induced photoaging, calcium channel release-activated calcium channel protein 1 (ORAI1) channel activity in HEK293T cells overexpressing TRPV1 or ORAI1 and STIM1. Electrophysiological analysis revealed that the butanol fraction inhibited capsaicin-induced TRPV1 $(84 \pm 8 \%$ at $-60 \mathrm{mV} / 86 \pm 1 \%$ at $100 \mathrm{mV}$ at $100 \mu \mathrm{g} / \mathrm{ml})$ and ORAI1 $(87 \pm 2 \%$ at $-120 \mathrm{mV}$ at $100 \mu \mathrm{g} / \mathrm{ml}$ ) currents. Furthermore, the dichloromethane and hexane fractions inhibited tyrosinase activity by $32.4 \pm 0.69$ and $22.6 \pm 0.96 \%$ at $330 \mu \mathrm{g} / \mathrm{ml}$, respectively. Furthermore, the ethylacetate and butanol fractions inhibited elastase activity by $65.2 \pm 1.30$ and $31.7 \pm 1.23 \%$ at $330 \mu \mathrm{g} / \mathrm{ml}$, respectively. Tyrosinase and elastase, which are UV-induced photoaging-associated enzymes, regulate skin pigmentation and wrinkle formation, respectively. The results of the present study indicated that $S$. plebeia leaves may be a novel treatment for UV-induced photoaging.

\section{Introduction}

The elderly population is rapidly growing, which has led to an increase in dermatological problems, including eczema, wrinkling and pigmentation. Skin aging is associated with several factors, including genetics, environment, hormonal changes and metabolic processes. Although all of these factors can contribute to skin aging, the environment, particularly solar ultraviolet (UV) radiation is a prominent mediator of skin aging (1-3). UV radiation exposure activates fibroblast and keratinocyte growth factor receptors, which activate the nuclear activator protein (AP)-1. This produces matrix metalloproteinases (MMPs), including collagenase (MMP-1), gelatinase B (MMP-9) and stromelysin-1 (MMP-3), which degrade collagen and elastic fibers, thereby inducing skin wrinkling and laxity $(4,5)$. Neutrophils also mediate sun-induced skin aging. Following UV radiation, neutrophils infiltrate the skin and release dermal elastase, a key elastolytic enzyme (6-8). Following skin exposure to UV radiation, the keratinocytes produce endothelins (ETs), which induce melanocyte proliferation and tyrosinase production. 
Tyrosinase is a key melanogenic enzyme that controls skin pigmentation $(9,10)$. Moreover, photoaged skin is functionally degenerated. The differentiation of keratinocytes, a component of the epidermis, is critical for the skin barrier function. As the skin ages, inhibition of keratinocyte differentiation disturbs the skin barrier, leading to allergen invasion, immunological reactions and inflammation. Therefore, skin barrier alterations induce inflammatory skin disease (11).

Intracellular calcium signaling mediates diverse skin processes, including barrier formation, cell differentiation, melanogenesis and tumor progression. These processes are regulated by several ion channels, including the transient receptor potential vanilloid 1 (TRPV1), which is associated with skin aging. TRPV1 is a nonselective cation channel with high calcium permeability, which responds to temperature, $\mathrm{pH}$ and vanilloids including capsaicin (12-14). TRPV1 in the skin mediates heat shock and UV radiation-induced MMP-1 expression (15). Furthermore, UV radiation, growth factors and cytokines induce MMP-mediated deterioration of dermal collagen, leading to skin wrinkling via inflammation, skin aging and tumor invasion $(5,16,17)$. Calcium also mediates epidermal melanin production in melanocytes. Of note, TRPV1 expression is functionally associated with calcium influx (18). In addition, the stimulation of TRPV1 by capsaicin or heat delays skin barrier recovery (19). Furthermore, capsaicin-mediated TRPV1 activation in keratinocytes produces inflammatory cytokines, suggesting a role in inflammatory skin disease (20). Calcium release-activated calcium modulator 1 (ORAI1) channels also perform important functions in the skin. Stromal interaction molecule (STIM)-gated ORAI1 channels are highly selective calcium channels that are activated by endoplasmic reticulum (ER) calcium depletion $(21,22)$. ORAI1 is essential for immune-cell function; however, a recent study indicated that ORAI1-mediated calcium uptake regulates keratinocyte proliferation and differentiation (23). ORAI1 calcium influx also regulates neutrophil activation, which triggers elastase release $(24,25)$ and endothelin-1 (ET-1)-mediated melanogenesis (9). Therefore, modulators of TRPV1 and ORAI1 channels may represent novel therapeutic agents for UV-induced photoaging.

Salvia plebeia $\mathrm{R} . \mathrm{Br}$. (Lamiaceae) (S. plebeia) is an annual or biennial plant that grows in numerous countries, including China, Korea and India. It is used as a traditional medicine to treat inflammatory diseases, including hepatitis, cough and hemorrhoids (26). Pharmacological investigations have revealed that of the leaf extract of S. plebeia has anti-oxidative (27), anti-tyrosinase (28), anti-cancer (29) and hepatoprotective effects (26). The active components of S. plebeia comprise flavonoids $(30,31)$, diterpenoids (32), lignin (33), aliphatic compounds (34) and sesquiterpenoids (35). Although S. plebeia leaves are used to prevent and treat skin aging-associated conditions, including inflammation, pigmentation and wrinkle formation, the exact underlying physicochemical and molecular mechanisms of its biological activity have remained elusive.

Therefore, the present study investigated whether S.plebeia leaves regulate the calcium concentration, a critical mediator of skin aging signaling pathways, via TRPV1 and ORAI1 channels. Its effects on tyrosinase and elastase, which are the major downstream enzymes in UV-induced photoaging, were also evaluated.

\section{Materials and methods}

Chemicals. All chemicals were purchased from Sigma-Aldrich (St. Louis, MO, USA), except 3,5-bis(trifluoromethyl)pyrazole (BTP2), which was obtained from Tocris (Bristol, UK). Stock solutions of capsaicin $(10 \mathrm{mM})$, inositol triphosphate $\left(\mathrm{InsP}_{3}\right.$; $20 \mathrm{mM})$, BTP2 (10 mM), and 4-(3-chloro-2-pyridinyl)- $N$-[4(1,1-dimethylethyl)phenyl]-1-piperazinecarboxamide (BCTC; $10 \mathrm{mM}$ ) were prepared in dimethyl sulfoxide (DMSO). All stock solutions were stored at $-20^{\circ} \mathrm{C}$.

Extraction. The dried and pulverized leaves of S. plebeia $(200 \mathrm{~g})$ were purchased from Omniherb drug store (Seoul, Korea) and extracted twice with 70\% methanol (1 l) under reflux to obtain the methanolic extract. After evaporation of the solvent, the solid extracted material was obtained (yield, $43.0 \mathrm{~g}$ ), which was then successively partitioned with n-hexane $(200 \mathrm{ml})$, dichloromethane $(200 \mathrm{ml})$, ethylacetate $(100 \mathrm{ml})$ and n-butanol $(100 \mathrm{ml})$ to obtain the corresponding fractions with yields of 1.8, 1.5, 2.4 and $5.0 \mathrm{~g}$, respectively. Dried extracts were diluted with DMSO to prepare stock solutions (30 and $100 \mathrm{mg} / \mathrm{ml}$ ) of each extract.

Gas chromatography-mass spectrometry (GC-MS) analysis. GC-MS (Agilent GC/Pegasus 4D, Agilent Technologies, Santa Clara, CA, USA) analyses of the dichloromethane and ethylacetate fractions were performed under the following conditions: Injector split ratio, 10:1; injection volume, $1.0 \mu \mathrm{l}$ dichloromethane solution; injector temperature, $250^{\circ} \mathrm{C}$; column, Agilent J\&W DM-5MS (30 m x 0.25 mm ID x $0.25 \mu \mathrm{m}$; Agilent Technologies); carrier gas, helium; flow rate, $1.0 \mathrm{ml} / \mathrm{min}$; oven temperature programming, $50^{\circ} \mathrm{C}(3 \mathrm{~min}) \rightarrow 10^{\circ} \mathrm{C} / \mathrm{min} \rightarrow 320^{\circ} \mathrm{C}$ (18 min). For the MS analysis, the following conditions were used: Ion source, electron impact; $230^{\circ} \mathrm{C}$; analyzer, quadrupole; $150^{\circ} \mathrm{C}$; mass range, $35-800 \mathrm{~m} / \mathrm{z}$ (mass-to-charge ratio).

Cell culture. HEK293T cells (American Type Culture Collection, Manassas, VA, USA) were maintained in Dulbecco's modified Eagle's medium (Thermo Fisher Scientific, Inc., Waltham, MA, USA) at $37^{\circ} \mathrm{C}$ in a humidified incubator containing $20 \% \mathrm{O}_{2}$ and $10 \% \mathrm{CO}_{2}$ (as $3.7 \mathrm{~g} / 1 \mathrm{NaHCO}_{3}$ requires $10 \%)$. All media were supplemented with $10 \%$ fetal bovine serum (WelGENE, Daegu, South Korea), $100 \mathrm{U} / \mathrm{ml}$ penicillin and $100 \mathrm{~g} / \mathrm{ml}$ streptomycin (Thermo Fisher Scientific, Inc.). The cells were subcultured every 2-3 days.

Transfection of TRPVI, ORAII and STIM1. For the patch clamp studies, the cells were transferred in $25-\mathrm{cm}^{2}$ culture flasks (Thermo Fisher Scientific, Inc.) 1 day prior to transfection. HEK293T cells were transiently transfected with a mammalian expression vector carrying human (h)TRPV1 or hORAI1 and hSTIM1 using the Turbofect transfection reagent (Thermo Fisher Scientific, Inc.) according to the manufacturer's instructions. In all transfection studies, the cells were co-transfected with a plasmid vector coding the enhanced green fluorescent protein (pEGFP-N1) to sort out the transfected cells. To record TRPV1 currents $\left(\mathrm{I}_{\mathrm{TRPV}}\right)$, 
hTRPV1 and pEGFP-N1 were co-transfected at a ratio of 9:1. To record ORAI1 currents $\left(\mathrm{I}_{\text {ORAI1 }}\right)$, hORAI1, hSTIM1 and pEGFP-N1 were triple-transfected at a ratio of 4.5:4.5:1, respectively. Human TRPV1 (hTRPV1) plasmid (pcDNA5/FRT) was generously donated by Dr Sung Joon Kim (Seoul National University, Seoul, Korea). Human ORAI1 (hOrai1) and human STIM1 (hSTIM1) were purchased from Origene Technologies (Rockville, MD, USA). hSTIM1 and hORAI1 cDNA were subcloned into pcDNA3.1 (Thermo Fisher Scientific, Inc.). Experiments were performed within 24-36 h of transfection.

Electrophysiology. Conventional whole-cell patch clamp methods were used to measure the hTRPV1 and hORAI1 currents at room temperature. Recordings were acquired using an Axopatch 700B amplifier interfaced with a Digidata 1440A (Molecular Devices, Sunnyvale, CA, USA). The recorded data were digitized at $10 \mathrm{kHz}$ and low-pass filtered at $5 \mathrm{kHz}$ using the pCLAMP 10.4 software (Molecular Devices). Patch pipettes were produced from thin-walled borosilicate glass (World Precision Instruments, Sarasota, FL, USA) using a horizontal Flaming Brown micropipette puller (model P-97). Pipette tips were fire-polished to a resistance of 2-3 MOhm to facilitate gigaseal formation (Narishige, East Meadow, NY, USA). The transfected cells were transferred to a perfusion chamber (Warner Instruments, Hamden, CT, USA) mounted on the stage of an inverted microscope (Nikon, Tokyo, Japan). Bath solutions were perfused at $3 \mathrm{ml} / \mathrm{min}$. To measure the hTRPV currents, voltage ramp protocols ranging from -100-100 mV over $100 \mathrm{msec}$ were applied every $20 \mathrm{sec}$ at a -10-mV holding potential. For hORAI1, ramp-like pulses from -130-70 mV over $100 \mathrm{msec}$ were applied every $30 \mathrm{sec}$ at a $-10-\mathrm{mV}$ holding potential to obtain the current-voltage association. The junction potentials were canceled prior to patch formation and pipette capacitances were compensated for electronically after gigaseal formation. All the voltage and current trace data were analyzed using the Clampfit software 10.4, Prism 6.0 (GraphPad, Inc., La Jolla, CA, USA) and Origin 8.0 (MicroCal, Northampton, MA, USA).

For the hTRPV1 whole-cell patch clamping, the external solution contained $140 \mathrm{mM} \mathrm{NaCl}, 4 \mathrm{mM} \mathrm{KCl}, 1 \mathrm{mM} \mathrm{MgCl}$, $1 \mathrm{mM}$ ethylene glycol tetraacetic acid (EGTA), $5 \mathrm{mM} \mathrm{D-glucose}$ and $10 \mathrm{mM}$ 4-(2-hydroxyethyl)-1-piperazineethanesulfonic acid (HEPES) ( $\mathrm{pH}$ 7.4). The internal solution contained $140 \mathrm{mM} \mathrm{CsCl}, 10 \mathrm{mM} \mathrm{NaCl}, 5 \mathrm{mM}$ EGTA, $3 \mathrm{mM}$ adenosine triphosphate magnesium salt and $10 \mathrm{mM}$ HEPES (pH 7.2). The capsaicin-evoked activity was observed by applying capsaicin $(1 \mu \mathrm{M})$ in the external solution after confirming the basal current. For the hORAI1 whole-cell patch clamp recording, the external solution contained $3.6 \mathrm{mM} \mathrm{KCl}, 10 \mathrm{mM} \mathrm{CaCl}$, $1 \mathrm{~mm} \mathrm{MgCl}_{2}, 5 \mathrm{mM}$ D-glucose, and $10 \mathrm{mM}$ HEPES (pH 7.4). The internal solution contained $130 \mathrm{mM}$ Cs-glutamate, $20 \mathrm{mM}$ 1,2-bis (o-aminophenoxy) ethane- $N, N, N^{\prime}, N^{\prime}$-tetracetic acid, $1 \mathrm{mM} \mathrm{MgCl} 2,3 \mathrm{mM} \mathrm{MgATP}, 0.002 \mathrm{mM}$ sodium pyruvate and $20 \mathrm{mM}$ HEPES (7.2). To activate the hORAI1 currents, $20 \mu \mathrm{M}$ $\mathrm{InsP}_{3}$ was added to the internal solution.

Tyrosinase assay. The tyrosinase inhibitory activity of $S$. plebeia was measured using a modified method (36). In brief, a mixture of sodium phosphate buffer ( $\mathrm{pH} 6.8 ; 0.066 \mathrm{M})$, L-3,4-dihydroxyphenylalanine $(1.5 \mathrm{mM})$ and DMSO
$(10 \mathrm{mg} / \mathrm{ml})$ was added to the enzyme solution $(500 \mathrm{U} / \mathrm{ml})$, and the mixture was incubated at $30^{\circ} \mathrm{C}$ for $10 \mathrm{~min}$. After enzyme inactivation using an ice bath, the optical density was measured using spectrophotometer (Ultraspec 2000; Amersham Pharmacia Biotech, NJ, USA) at a wavelength of $475 \mathrm{~nm}$. Kojic acid $(200 \mu \mathrm{g} / \mathrm{ml})$ was used as a positive control.

Elastase assay. Inhibition of porcine pancreatic elastase was estimated using a modified method (37). In brief, a mixture of Tris- $\mathrm{HCl}$ buffer $(\mathrm{pH} 8.0 ; 0.1 \mathrm{M})$, $N$-succinyl-Ala-Ala-Ala-p-nitroanilide $(1 \mathrm{mM})$ and sample solution (plant extract or fractions, $10 \mathrm{mg} / \mathrm{ml}$ in DMSO) was added to the enzyme solution (elastase in Tris- $\mathrm{HCl}$ buffer, $0.1 \mathrm{U} / \mathrm{ml}$ ), followed by incubation at $25^{\circ} \mathrm{C}$ for $20 \mathrm{~min}$. After enzyme inactivation using an ice bath, the optical density was measured at a wavelength of $410 \mathrm{~nm}$ using an Ultraspec 200 spectrophotometer. Ursolic acid $(200 \mu \mathrm{g} / \mathrm{ml})$ was used as a positive control.

Statistical analysis. Values are expressed as the mean \pm standard error of the mean. The $\mathrm{N}$ values indicate the number of separate cells used in the experiment. Comparison tests were performed using one-way analysis of variance with Bonferroni's post-hoc comparison. $\mathrm{P}<0.05$ was considered to indicate a statistically significant difference. Prism 6.0 software (GraphPad, Inc.) and Origin 8.0 (MicroCal) were used for statistical analyses.

\section{Results}

S. plebeia extracts inhibit the basal $I_{\mathrm{TRPV} 1}$ and $I_{\mathrm{ORA} 1}$. To evaluate whether TRPV1 and ORAI1 are affected by the S. plebeia leaf crude extract and fractions, whole-cell currents in HEK293T cells overexpressing TRPV1 or ORAI1 and STIM1 were measured. To evaluate the inhibitory effects of this herbal extract on the basal $\mathrm{I}_{\mathrm{TRPV} 1}, 1 \mathrm{mM}$ capsaicin was used to activate $\mathrm{I}_{\mathrm{TRPV} 1}$. After confirming the $\mathrm{I}_{\mathrm{TRPV} 1}$ steady state, 10,30 or $100 \mu \mathrm{g} / \mathrm{ml}$ of the extract or fractions were added to the external solution. A total of $1 \mu \mathrm{M}$ of the selective TRPV1 inhibitor BCTC was used as a positive control. Fig. 1A shows a typical data recording for the capsaicin-induced $\mathrm{I}_{\mathrm{TRPV} 1}$ and its inhibition by the butanolic fraction. The associated I-V curves at (a) the peak $\mathrm{I}_{\mathrm{TRPV} 1}$ and at (b) 10, (c) 30, and (d) $100 \mu \mathrm{g} / \mathrm{ml}$ butanolic fraction were achieved using a ramp-like pulse protocol from $-100-100 \mathrm{mV}$ (Fig. 1B). Fig. 1B further shows that the application of capsaicin produced a strong outward rectifying current potential reversal $(0 \mathrm{mV})$. To analyze the fraction-induced inhibition, the normalized amplitudes of the fraction-treated currents ( $\left.\mathrm{I} / \mathrm{I}_{\mathrm{con}} \mathrm{x} 100 \%\right)$ were obtained at 100 - and $-60-\mathrm{mV}$ clamp voltages. As shown in Fig. $1 \mathrm{C}$, the level of $\mathrm{I}_{\mathrm{TRPV} 1}$ inhibition by the butanolic fraction at $-60 \mathrm{mV}$ was $5 \pm 11,39 \pm 10$ and $84 \pm 8 \%$ at 10,30 and $100 \mu \mathrm{g} / \mathrm{ml}$, respectively, and at $100 \mathrm{mV}$, it was $4 \pm 9,37 \pm 4$ and $86 \pm 1 \%$ at 10 , 30 and $100 \mu \mathrm{g} / \mathrm{ml}$, respectively.

To evaluate the inhibition of $\mathrm{I}_{\mathrm{ORAI}}, 20 \mu \mathrm{M}$ InsP $\mathrm{P}_{3}$ was added to the internal solution in order to deplete ER calcium stores. When the ER calcium concentration drops, STIM1 binds to and activates ORAI1, and thereby allows for calcium entry. After obtaining the whole-cell configuration, an inwardly rectifying current with reversal potential at $50 \mathrm{mV}$ was obtained 


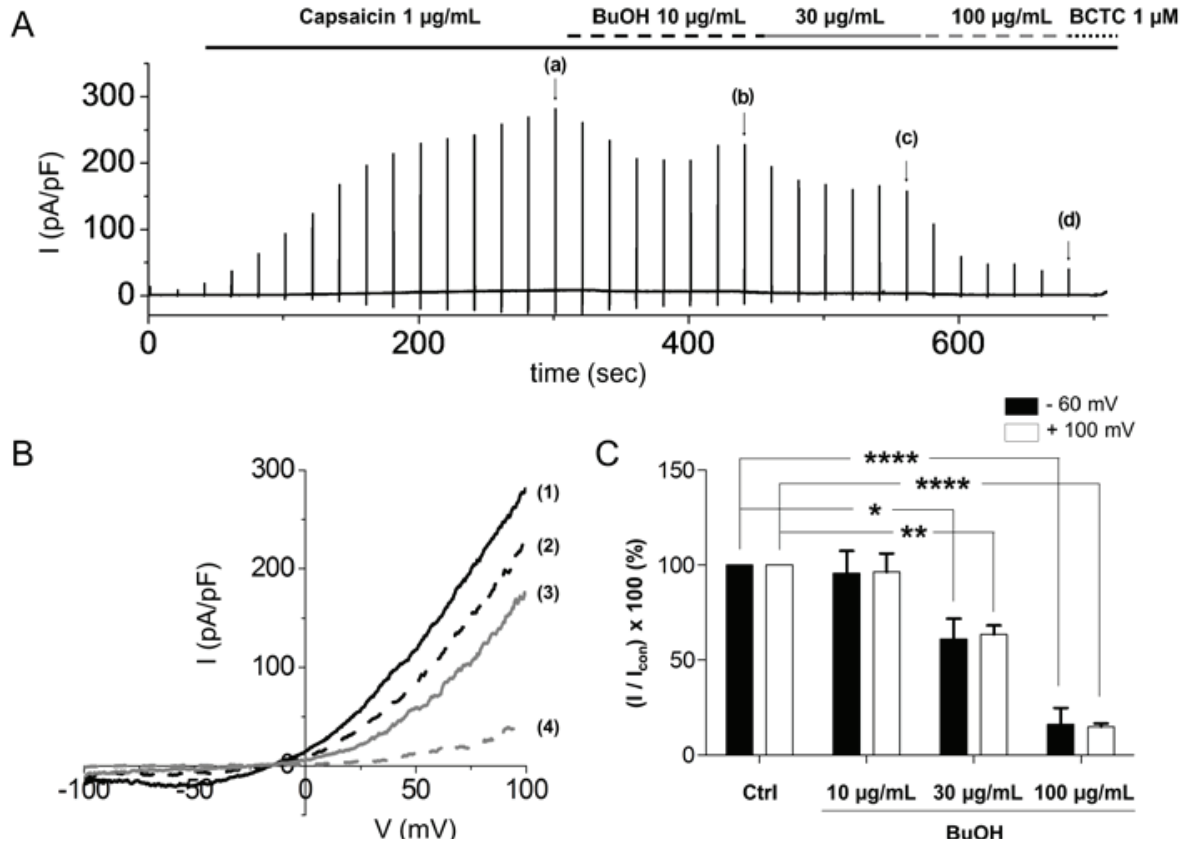

Figure 1. Effects of Salvia plebeia butanolic fraction on $\mathrm{I}_{\mathrm{TRPV} 1}$. (A) Representative tracing of $\mathrm{I}_{\mathrm{TRPV} 1}$ inhibition by S. plebeia butanol fraction. After confirming $\mathrm{I}_{\mathrm{TRPV} 1}$ activation using $1 \mu \mathrm{M}$ capsaicin, 10,30 or $100 \mu \mathrm{g} / \mathrm{ml}$ butanolic fraction was applied to hTRPV1-overexpressing HEK293T cells. (B) Corresponding I-V association curve of control (a) peak current and (b) 10, (c) 30 and (d) $100 \mu \mathrm{g} / \mathrm{ml}$ butanolic fraction. (C) Summary of butanolic fraction-induced I $\mathrm{I}_{\mathrm{TRPV}} \mathrm{inhibition}$ rates at -60 and $100 \mathrm{mV} .{ }^{*} \mathrm{P}<0.05,{ }^{* *} \mathrm{P}<0.01$ and ${ }^{* * * * *} \mathrm{P}<0.0001$ vs. control for each. I, current; V, voltage; Ctrl/Con, control; hTRPV1, human transient receptor potential vanilloid 1; BCTC, 4-(3-chloro-2-pyridinyl)- $N$-[4-(1,1-dimethylethyl)phenyl]-1-piperazinecarboxamide; BuOH, butanolic fraction of Salvia plebeia .

in the ORAI1/STIM1 co-transfected cells. After confirming the steady state of the $\mathrm{I}_{\text {ORAII }}, 10,30$ or $100 \mu \mathrm{g} / \mathrm{ml}$ extract or fraction of S. plebeia leaf was added to the bath solution to analyze the S. plebeia-mediated inhibition of ORAI1. BTP2 $(10 \mu \mathrm{M})$, which is a selective ORAI1 inhibitor, was added to the external solution to confirm the basal current. As presented in Fig. 2A, the serial application of 10, 30 and $100 \mu \mathrm{g} / \mathrm{ml}$ of the butanolic fraction inhibited $\mathrm{I}_{\mathrm{ORAII}}$. Fig. 2B shows the I-V association curve between the (a) control and butanolic fraction treatment at (b) 10 , (c) 30 and (d) $100 \mu \mathrm{g} / \mathrm{ml}$. At $-120 \mathrm{mV}$, the butanolic fraction inhibited $\mathrm{I}_{\text {ORAII }}$ by $31 \pm 5,62 \pm 5$ and $87 \pm 2 \%$ at 10,30 and $100 \mu \mathrm{g} / \mathrm{ml}$, respectively (Fig. 2C; $\mathrm{n}=6$ ). The hexane fraction had a greater inhibitory effect on $\mathrm{I}_{\text {ORAII }}$ than the butanolic fraction (Fig. 3); at $-120 \mathrm{mV}$, the hexane fraction inhibited $\mathrm{I}_{\text {ORAII }}$ by $56 \pm 2,82 \pm 1$ and $92 \pm 2 \%$ at 10,30 and $100 \mu \mathrm{g} / \mathrm{ml}$, respectively (Fig. 3C; $n=7$ ). The TRPV1 and ORAI1 inhibition rates are presented in Table I. The butanolic fraction had the strongest effect on $\mathrm{I}_{\mathrm{TRPV} 1}$ and $\mathrm{I}_{\mathrm{ORAII}}$.

S. plebeia extracts inhibit tyrosinase. To verify the skin-lightening effects of the S. plebeia leaves tyrosinase assays were performed using the extract and fractions. Tyrosinase is a key enzyme that initiates melanogenesis. Decreased tyrosinase activity corresponds with reduced melanin production. kojic acid, a tyrosinase inhibitor, was used as a positive control $(80.7 \pm 0.69 \%)$. As shown in Fig. 4, the dichloromethane $(32.4 \pm 0.69 \%)$ and hexane $(22.6 \pm 0.96 \%)$ fractions inhibited tyrosinase activity.

S. plebeia extracts inhibit elastase. Elastase regulates wrinkle formation by deteriorating and remodeling the extracellular matrix. Therefore, elastase assays can be used to evaluate the effect of S. plebeia on wrinkle formation. Ursolic acid, an elastase inhibitor, was used as a positive control $(83.9 \pm 0.79 \%)$. As presented in Fig. 5, the ethylacetate and butanolic fractions inhibited elastase by $65.2 \pm 1.30$ and $31.7 \pm 1.23 \%$, respectively.

\section{$G C-M S$}

Molecular composition of S. plebeia extracts. As outlined in Fig. 6, the total ion GC-MS chromatogram of the most active dichloromethane fraction revealed phytol as a main compound (5.37\%) in addition to minor sterol components, including 23-ethylcholest-5-en-3-ol (0.60\%), stigmasterol $(0.39 \%)$ and ergost-5-en-3-ol $(0.24 \%)$. The ethyl acetate fraction contained hispidulin (4',5,7-trihydroxy-6-methoxyflavone) as a major constituent (30.4\%) in addition to minor amounts of phenolic compounds (including 4-vinylguaiacol and 3-allyl-2-methoxyphenol).

\section{Discussion}

The use of natural products in the prevention and treatment of skin aging, particularly pigmentation and wrinkling, has aroused great interest. Solar UV radiation damage is of considerable importance in skin aging (1-3). Recently, S. plebeia, which is traditionally used to treat inflammatory diseases (26), has gained attention owing to its skin-whitening and elasticity effects. However, its anti-skin aging effect and the underlying biological mechanisms have remained elusive. Therefore, the present study examined the effects of S. plebeia leaves on the photoaging-associated ion channels TRPV1 and ORAI1, as 

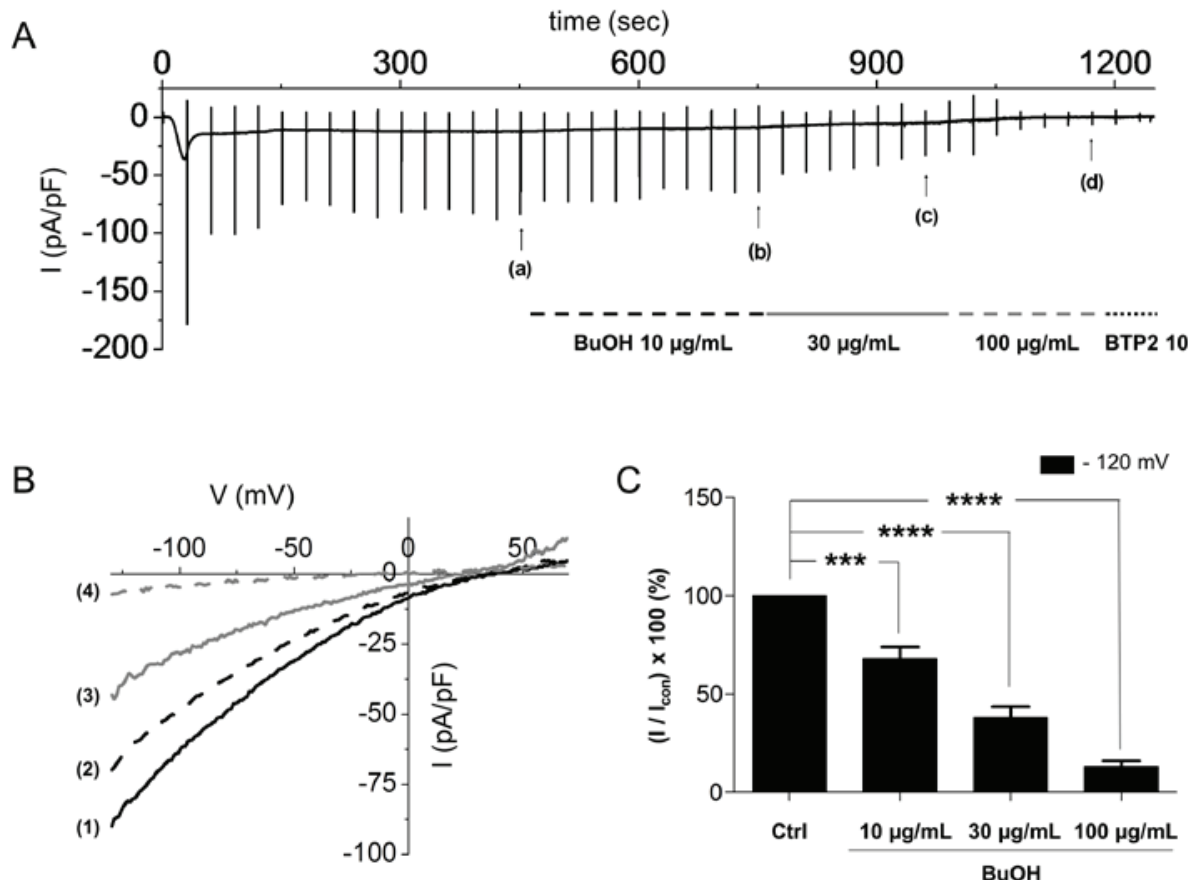

Figure 2. Effects of Salvia plebeia butanolic fraction on $\mathrm{I}_{\mathrm{ORAII}}$. (A) Representative tracing of $\mathrm{I}_{\mathrm{ORAII}}$ inhibition by S. plebeia butanolic fraction. After confirming $\mathrm{I}_{\text {ORAII }}$ activation using $20 \mu \mathrm{M}$ inositol triphosphate, 10,30 or $100 \mu \mathrm{g} / \mathrm{ml}$ butanolic fraction was applied to hORAI1- and stromal interaction molecule-overexpressing HEK293T cells. (B) Corresponding I-V association curve of (a) control current and (b) 10, (c) 30 and (d) $100 \mu \mathrm{g} / \mathrm{ml}$ butanolic fraction. (C) Summary of butanol fraction-induced $\mathrm{I}_{\text {ORAII }}$ inhibition rates at $-120 \mathrm{mV} .{ }^{* * * * *} \mathrm{P}<0.001$ and ${ }^{* * * * *} \mathrm{P}<0.0001$ vs. control for both. I, current; V, voltage; Ctrl/Con, control; hTRPV1, human transient receptor potential vanilloid 1; BTP2, 3,5-bis(trifluoromethyl)pyrazole; hORAI1, human calcium release-activated calcium modulator 1; $\mathrm{BuOH}$, butanolic fraction of Salvia plebeia.
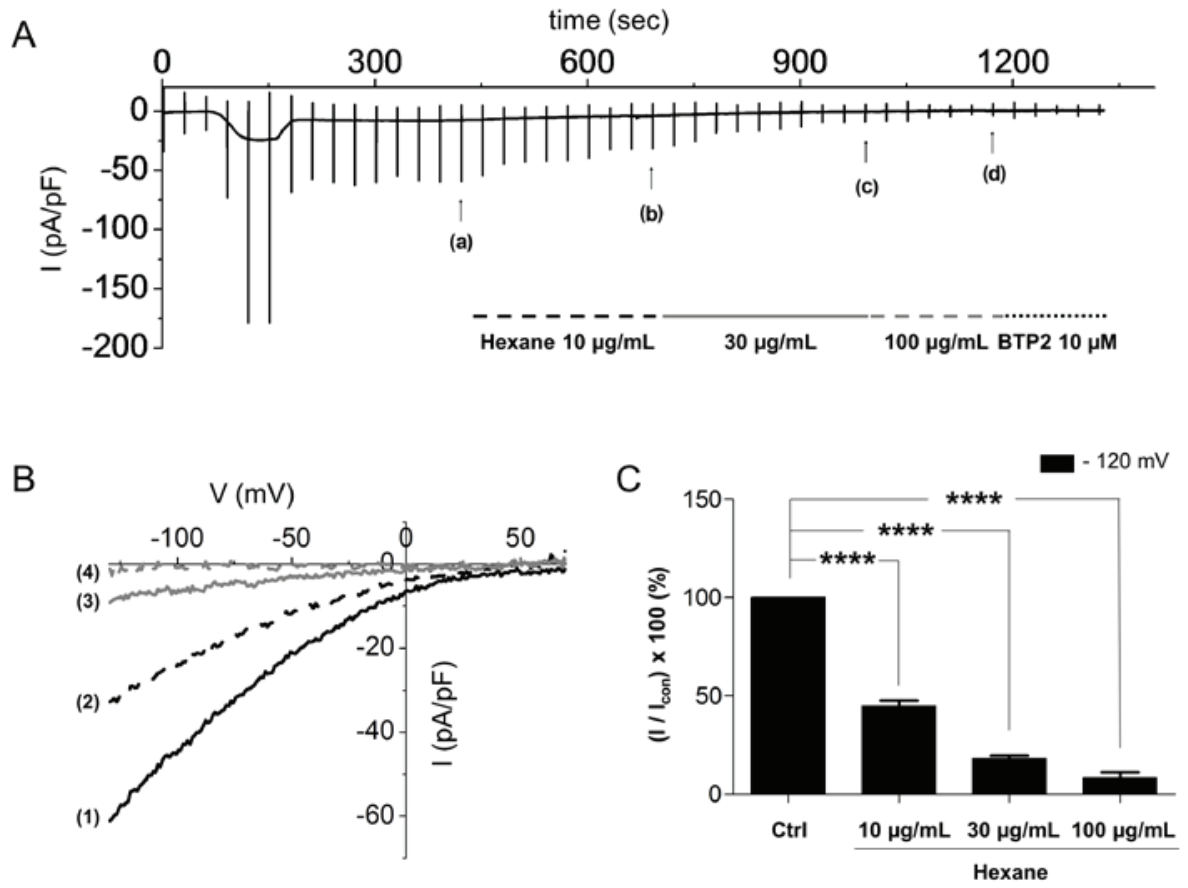

Figure 3. Effects of the Salvia plebeia hexane fraction on $\mathrm{I}_{\text {ORAII }}$. Representative tracing showing effect of hexane fraction on (A) $\mathrm{I}_{\mathrm{ORAII}}$ and (B) the corresponding $\mathrm{I}-\mathrm{V}$ association curve at different times after treatment. (C) Summary of percentage change in $\mathrm{I}_{\text {ORAIl }}$ caused by hexane fraction at $-120 \mathrm{mV}$. ${ }^{* * * * *} \mathrm{P}<0.0001 \mathrm{vs}$. control. I, current; V, voltage; Ctrl/Con, control; BTP2, 3,5-bis(trifluoromethyl)pyrazole; hORAI1, human calcium release-activated calcium modulator 1; hexane, hexane fraction of Salvia plebeia.

well as on the photoaging-associated enzymes tyrosinase and elastase.
In keratinocytes, TRPV1 mediates UV-induced MMP-1, which destroys collagen. Following exposure to UV 


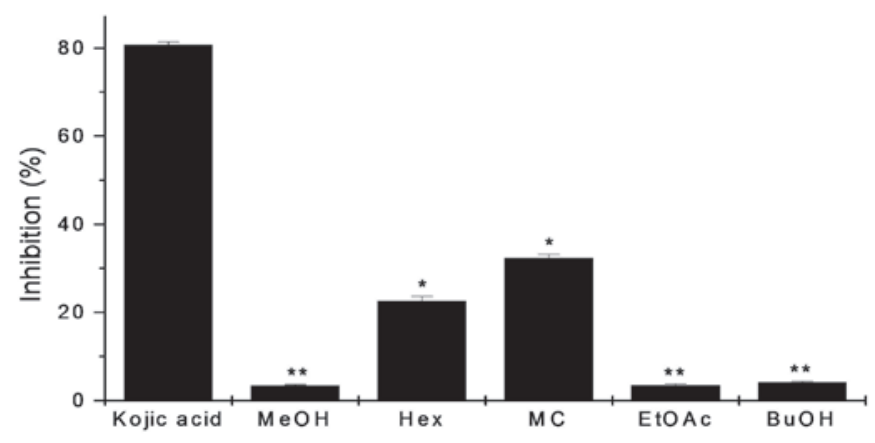

Figure 4. Inhibitory activity of Salvia plebeia extract and fractions on tyrosinase activity. $\mathrm{MeOH}$, methanolic extract; $\mathrm{MC}$, dichloromethane fraction; EtOAc, ethyl acetate fraction; $\mathrm{BuOH}$, n-butanol fraction; Hex, hexanol fraction. Kojic acid was used as a positive control. ${ }^{*} \mathrm{P}<0.05$ and ${ }^{* *} \mathrm{P}<0.01$ compared to kojic acid.

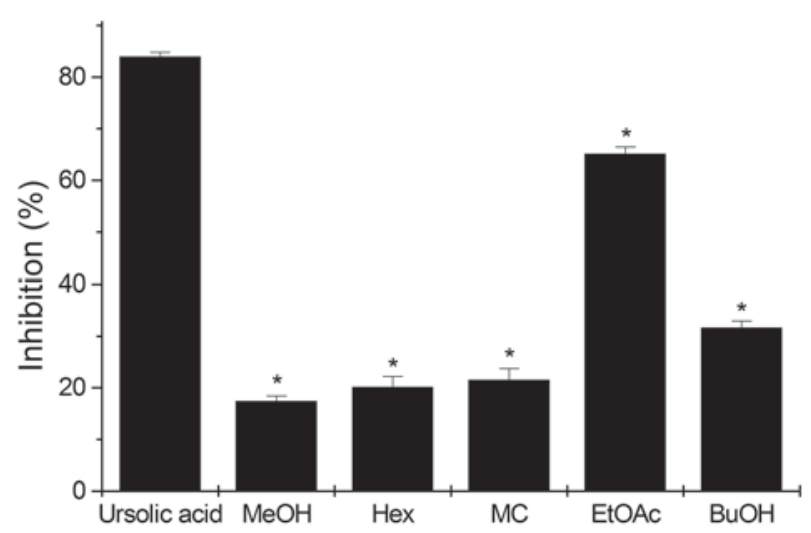

Figure 5. Inhibitory activity of Salia plebeia extract and fractions on elastase activity. $\mathrm{MeOH}$, methanolic extract; $\mathrm{MC}$, dichloromethane fraction; EtOAc, ethyl acetate fraction; $\mathrm{BuOH}$, n-butanol fraction; Hex, hexanol fraction. Ursolic acid was used as a positive control. ${ }^{*} \mathrm{P}<0.05$ compared to ursolic acid.

radiation, TRPV1 induces calcium influx, thereby activating calcium-dependent protein kinase $\mathrm{C}$ and promoting MMP-1 expression $(15,38)$. A previous study suggested that TRPV1 is associated with melanogenesis due to changes in TRPV1 expression and calcium uptake (18). ORAI1, which regulates calcium uptake, regulates melanogenesis and neutrophil activation $(9,24,25)$. Following UV radiation, the ORAI1-dependent calcium influx mediates ET-1-induced melanogenesis and the release of collagen and elastic fiber-degrading enzymes in neutrophils (9). In the present study, electrophysiological analysis indicated that the butanolic fraction $(100 \mu \mathrm{g} / \mathrm{ml})$ inhibited TRPV1 activity by $84 \pm 8$ and $86 \pm 1 \%$ at -60 and $100 \mathrm{mV}$, respectively. Furthermore, $-120 \mathrm{mV}$, the hexane and butanolic fractions $(100 \mu \mathrm{g} / \mathrm{ml}$ each) strongly inhibited ORAI1 activity by $92 \pm 2$ and $87 \pm 2 \%$, respectively. Therefore, $S$. plebeia leaves inhibited the upstream signaling pathways regulating UV-induced skin wrinkle formation and pigmentation. Studies indicated that TRPV1 activation is involved in delayed skin barrier recovery and cutaneous inflammation $(19,20)$. Therefore, S.plebeia may also prevent skin inflammation. In the present study, to determine whether the leaf extract and fractions of $S$. plebeia were able to inhibit tyrosinase and elastase, which are the mediators of UV photoaging, tyrosinase and elastase assays were performed. Tyrosinase regulates the synthesis of melanin, thereby determining skin pigmentation (10). Although the inhibitory efficacy was not strong, the dichloromethane and hexane fractions inhibited tyrosinase activity by $32.4 \pm 0.69$ and $22.6 \pm 0.96 \%$, respectively. Elastase activity has a pivotal role in UV-induced wrinkling $(4,5)$ and the effect of S. plebeia on elastase was therefore assessed in the present study. The ethylacetate and butanolic fractions inhibited elastase by $65.2 \pm 1.30$ and $31.7 \pm 1.23 \%$, respectively; however, these fractions were less effective than ursolic acid, but had a relatively high efficacy. In addition, the GC-MS results revealed that the dichloromethane and ethyl acetate fractions contained phytol and hispidulin, respectively, as a main component. Phytol, a diterpene compound, has been reported to have a skin-whitening effect, which was determined by measuring tyrosinase promoter activity (39). To the best of our knowledge, the elastase inhibitory activity of hispidulin has not yet been reported. Furthermore, it has not been reported that phytol and hispidulin regulate the activity of TRPV1 and ORAI1 channels. Therefore, S. plebeia leaves may contain chemical constituents that directly inhibit enzyme activity associated with UV-induced photoaging.

In addition to its role in skin aging, TRPV1 is well known as a nociceptor activated by pain-producing stimuli, such as vanilloid compounds, moderate heat $\left(43^{\circ} \mathrm{C}\right)$ and low $\mathrm{pH}$ $(<5.9) \quad(12,40)$. TRPV1 is enriched in small-diameter, A $\delta$ and $\mathrm{C}$ fiber sensory neurons and has a significant role in pain sensation and neurogenic inflammation (40-42). Activation of TRPV1 in sensory fibers results in the release of neuropeptides, such as substance P and calcitonin gene-related peptide (43). The released peptides induces the release of pro-inflammatory and vasoactive substances causing neurogenic inflammation, such as increased blood flow and edema in cells including keratinocytes, mast cells and fibroblast (43). Analysis of TRPV1 knockout mice demonstrated that TRPV1 has a functional role in pain transduction and neurogenic inflammation, as indicated by an increased threshold to noxious heat and decreased tissue swelling in inflammation $(13,44,45)$. Therefore, studies have been performed to identify agents with the ability to inhibit TRPV1 channel activity for the development of novel analgesic therapeutics. ORAI1 is also a representative ion channel-regulating immune-cell activator. ORAI1 is distributed in T cells, B cells and mast cells, and ORAI1-mediated calcium signaling is essential to the immune response (46-49). Based on previously reported findings, T- and B-cell mediated immunity is severely impaired in human as well as mice in the absence of ORAI1 function $(46,47,50)$. Therefore, much work has focused on the inhibition of ORAI1 channel activity to suppress undesirable immune responses. Also, S. plebeia has been traditionally used to treat inflammatory diseases such as hepatitis, cough, and hemorrhoids (26) and recently, pharmacological studies have demonstrated that the leaf extract has anti-inflammatory and anti-nociceptive activities $(51,52)$. In addition, it was reported that its extract has an inhibitory effect on inflammatory arthritis in human rheumatoid synovial fibroblasts and a murine model (53), and in a mouse model of atopic dermatitis, its oral administration lessened atopic dermatitis symptoms and suppressed the expression of cytokines and chemokines (54). Thus, given these additional effects of 
Table I. Effects of Salvia plebeia extract and organic fractions on $\mathrm{I}_{\mathrm{TRPV} 1}$ and $\mathrm{I}_{\mathrm{ORAI} 1}$ currents $\left[\left(\mathrm{I} / \mathrm{I}_{\mathrm{con}}\right) \mathrm{x} 100(\%)\right]$.

\begin{tabular}{|c|c|c|c|c|c|c|c|c|c|}
\hline & \multicolumn{9}{|c|}{ Clamp voltage $(\mathrm{mV})$} \\
\hline & \multicolumn{6}{|c|}{ TRPV1 } & \multicolumn{3}{|c|}{ Orai1 } \\
\hline & \multicolumn{3}{|c|}{-60} & \multicolumn{3}{|c|}{100} & \multicolumn{3}{|c|}{-12} \\
\hline \multirow[t]{2}{*}{ Group } & \multicolumn{6}{|c|}{ Salvia plebia extract concentration $(\mu \mathrm{g} / \mathrm{ml})$} & & & \\
\hline & 10 & 30 & 100 & 10 & 30 & 100 & 10 & 30 & 100 \\
\hline Control & 100 & 100 & 100 & 100 & 100 & 100 & 100 & 100 & 100 \\
\hline $\mathrm{MeOH}$ extract $(n \leq 7)$ & $203 \pm 49$ & $268 \pm 80$ & $278 \pm 66$ & $138 \pm 8$ & $162 \pm 11$ & $164 \pm 15$ & $90 \pm 1$ & $73 \pm 2$ & $33 \pm 6$ \\
\hline$n-\mathrm{BuOH}$ fraction $(\mathrm{n} \leq 6)$ & $95 \pm 11$ & $61 \pm 10$ & $16 \pm 8$ & $96 \pm 9$ & $63 \pm 4$ & $14 \pm 1$ & $69 \pm 5$ & $38 \pm 5$ & $13 \pm 2$ \\
\hline $\mathrm{CH}_{2} \mathrm{Cl}_{2}$ fraction $(\mathrm{n} \leq 8)$ & $157 \pm 16$ & $261 \pm 49$ & $330 \pm 84$ & $119 \pm 3$ & $140 \pm 12$ & $139 \pm 21$ & $84 \pm 2$ & $51 \pm 6$ & $26 \pm 5$ \\
\hline EtOAc fraction $(n \leq 6)$ & $155 \pm 15$ & $250 \pm 40$ & $434 \pm 112$ & $128 \pm 7$ & $166 \pm 19$ & $205 \pm 28$ & $88 \pm 4$ & $77 \pm 5$ & $64 \pm 4$ \\
\hline Hexane fraction $(n \leq 7)$ & $158 \pm 18$ & $206 \pm 31$ & $273 \pm 50$ & $131 \pm 10$ & $152 \pm 8$ & $154 \pm 11$ & $44 \pm 2$ & $18 \pm 1$ & $8 \pm 2$ \\
\hline
\end{tabular}

Results are normalized amplitudes of fraction-treated currents $\left(\mathrm{I} / \mathrm{I}_{\mathrm{con}} \mathrm{x} 100 \%\right)$ measured at -60 and $100 \mathrm{mV}$ clamp voltage for TRPV1 current and $-120 \mathrm{mV}$ clamp voltage for ORAI1 current, and are presented as the mean \pm standard error of the mean. TRPV1, transient receptor potential vanilloid 1; ORAI1, calcium release-activated calcium modulator 1; I, current.

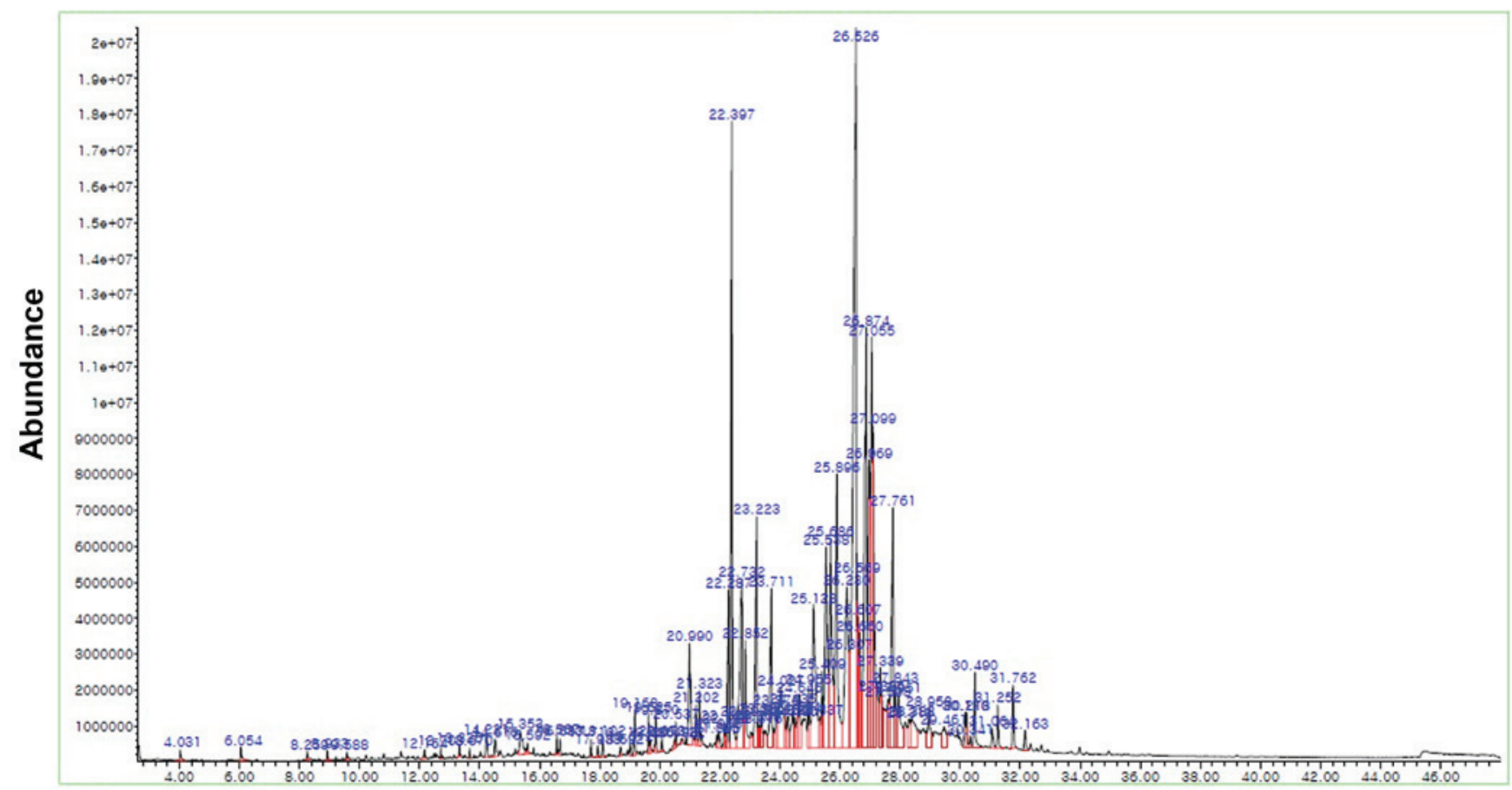

Time

Figure 6. Total ion chromatogram of the dichloromethane fraction of Salia plebeia extract. Peaks having more than 95\% quality are presented as follows: Rt $(\mathrm{min})=22.40$ : phytol; 22.73: linolenic acid; 30.22: 0-tocopherol; 31.07: ergost-5-en-3-ol; 31.26: stigmasterol, 31.76; and 23-ethylcholest-5-en-3-ol.

S. plebeia, it may be applied not only as an anti-skin aging agent but also as an anti-inflammatory or analgesic agent.

In conclusion, the results of the present study suggested that S. plebeia leaves may have therapeutic effects on UV-induced photoaging mediated by inhibiting upstream signaling pathway-associated ion channels and downstream enzyme activity. These findings may explain the mechanism of the anti-skin aging effects of this herbal drug and suggest a novel application of this extract. Furthermore, the present study was the first to provide an electrophysiological assessment of the effects of S. plebeia leaves on TRPV1 and ORAI1 channels.

\section{Acknowledgements}

This study was supported by a grant from the Korea Health Technology R\&D Project, Ministry of Health \& Welfare, 
Republic of Korea (grant no. HN14C0100) and was also partially supported by the Convergence of Conventional Medicine and Traditional Koran Medicine R\&D program funded by the Ministry of Health \& Welfare through the Korean Health Industry Development Institute (grant no. HI15C0256). The authors would like to thank Ms. Mi-Ok Lee (Department of Physiology, Dongguk University College of Medicine) for technical support.

\section{References}

1. Farage MA, Miller KW, Elsner P and Maibach HI: Characteristics of the aging skin. Adv Wound Care 2: 5-10, 2013.

2. Farage MA, Miller KW, Elsner P and Maibach HI: Intrinsic and extrinsic factors in skin ageing: A review. Int J Cosmet Sci 30: 87-95, 2008

3. Jenkins G: Molecular mechanisms of skin ageing. Mech of Ageing Dev 123: 801-810, 2002.

4. Fisher GJ and Voorhees JJ: Molecular mechanisms of retinoid actions in skin. FASEB J 10: 1002-1013, 1996.

5. Fisher GJ, Wang ZQ, Datta SC, Varani J, Kang S and Voorhees JJ: Pathophysiology of premature skin aging induced by ultraviolet light. N Engl J Med 337: 1419-1428, 1997.

6. Rijken F, Kiekens RC and Bruijnzeel PL: Skin-infiltrating neutrophils following exposure to solar-simulated radiation could play an important role in photoageing of human skin. Br J Dermatol 152: 321-328, 2005.

7. Rijken F, Kiekens RC, van den Worm E, Lee PL, van Weelden H and Bruijnzeel PL: Pathophysiology of photoaging of human skin: Focus on neutrophils. Photochem Photobiol Sci 5: 184-189, 2006.

8. Rijken F and Bruijnzeel PL: The pathogenesis of photoaging: The role of neutrophils and neutrophil-derived enzymes. J Investig Dermatol Symp Proc 14: 67-72, 2009.

9. Stanisz H, Stark A, Kilch T, Schwarz EC, Mller CS, Peinelt C, Hoth M, Niemeyer BA, Vogt T and Bogeski I: ORAI1 Ca(2+) Channels Control Endothelin-1-Induced mitogenesis and melanogenesis in primary human melanocytes. J Investig Dermatol 132 1443-1451, 2012.

10. Hearing VJ: Determination of melanin synthetic pathways. J Invest Dermatol 131: E8-E11, 2011.

11. Proksch E, Brandner JM and Jensen JM: The skin: An indispensable barrier. Exp Dermatol 17: 1063-1072, 2008.

12. Starowicz K, Nigam S and Di Marzo V: Biochemistry and pharmacology of endovanilloids. Pharmacol Ther 114: 13-33, 2007.

13. Alawi K and Keeble J: The paradoxical role of the transient receptor potential vanilloid 1 receptor in inflammation. Pharmacol Ther 125: 181-195, 2010.

14. Piper AS, Yeats JC, Bevan S and Docherty RJ: A study of the voltage dependence of capsaicin-activated membrane currents in rat sensory neurones before and after acute desensitization. J Physiol 518 (Pt 3): 721-733, 1999.

15. Li WH, Lee YM, Kim JY, Kang S, Kim S, Kim KH, Park CH and Chung JH: Transient receptor potential vanilloid-1 mediates heat-shock-induced matrix metalloproteinase-1 expression in human epidermal keratinocytes. J Invest Dermatol 127: 2328-2335, 2007.

16. Vincenti MP and Brinckerhoff CE: Transcriptional regulation of collagenase (MMP-1, MMP-13) genes in arthritis: Integration of complex signaling pathways for the recruitment of gene-specific transcription factors. Arthritis Res 4: 157-164, 2002

17. Fisher GJ, Kang S, Varani J, Bata-Csorgo Z, Wan Y, Datta S and Voorhees JJ: Mechanisms of photoaging and chronological skin aging. Arch Dermatol 138: 1462-1470, 2002.

18. Choi TY, Park SY, Jo JY, Kang G, Park JB, Kim JG, Hong SG, Kim CD, Lee JH and Yoon TJ: Endogenous expression of TRPV1 channel in cultured human melanocytes. J Dermatol Sci 56 128-130, 2009.

19. Denda M, Sokabe T, Fukumi-Tominaga T and Tominaga M: Effects of skin surface temperature on epidermal permeability barrier homeostasis. J Invest Dermatol 127: 654-659, 2007.

20. Jain A, Brönneke S, Kolbe L, Stäb F, Wenck H and Neufang G: TRP-channel-specific cutaneous eicosanoid release patterns. Pain 152: 2765-2772, 2011.

21. Prakriya M: Store-operated Orai channels: Structure and function. Curr Top Membr 71: 1-32, 2013.
22. Vig M, Peinelt C, Beck A, Koomoa D, Rabah D Koblan-Huberson M, Kraft S, Turner H, Fleig A, Penner R and Kinet JP: CRACM1 is a plasma membrane protein essential for store-operated Ca2+ entry. Science 312: 1220-1223, 2006.

23. Numaga-Tomita $T$ and Putney JW: Role of STIM1- and Orai1-mediated $\mathrm{Ca} 2+$ entry in $\mathrm{Ca} 2+-$-induced epidermal keratinocyte differentiation. J Cell Sci 126 (Pt 2): 605-612, 2013.

24. Grupe M, Myers G, Penner R and Fleig A: Activation of store-operated I(CRAC) by hydrogen peroxide. Cell Calcium 48: $1-9,2010$

25. Yang SC, Sung PJ, Lin CF, Kuo J, Chen CY and Hwang TL: Anti-inflammatory effects of secondary metabolites of marine pseudomonas sp. In human neutrophils are through inhibiting P38 MAPK, JNK and calcium pathways. PloS One 9: e114761, 2014.

26. Jin XF, Lu YH, Wei DZ and Wang ZT: Chemical fingerprint and quantitative analysis of Salvia plebeia $\mathrm{R}$. Br. by high-performance liquid chromatography. J Pharm Biomed Anal 48: 100-104, 2008.

27. Lim JA, Yun BW and Baek SH: Antioxidative activity and nitrite scavenging ability of methanol extract from Salvia plebeia $\mathrm{R}$. Br. Korean J Med Crop Sci 15: 183-188, 2007.

28. Kim SJ and Son KH: Tyrosinase inhibitory activity of 80 plant extracts (2). Biomol Ther 11: 5-7, 2003.

29. Bhanot A, Sharma R and Noolvi MN: Natural sources as potential anti-cancer agents: A review. Int J Phytomed 3: 9-26, 2011.

30. Gupta HC, Ayengar KN and Rangaswami S: Structure and synthesis of salvitin, a new flavone isolated from Salvia plebeia. Indian J Chem 13: 215-217, 1975.

31. Gu L and Weng X: Antioxidant activity and components of Salvia plebeia R. Br.- a Chinese herb. Food Chemistry 73: 299-305, 2001.

32. García-Alvarez MC, Hasan M, Michavila A, Fernández-Gadea F and Rodríguez B: Epoxysalviacoccina, neo-clerodane diterpenoid from Salvia plebeia. Phy tochemistry 25: 272-274, 1985.

33. Plattner RD and Powell RG: A secoisolariciresinol branched fatty diester from Salvia plebeia seed. Phytochemistry 17: 149-150, 1978.

34. Tripathi S, Asthana R and Ali A: Isolation and characterization of 5-ethylhentriacontane and nonacosane from Salvia plebeia. Asian J Chem 18: 1554-1556, 2006.

35. Cao SY, Ke ZL and Xi LM: A new sesquiterpene lactone from Salvia plebeia. J Asian Nat Prod Res 15: 404-407, 2013.

36. Tajima R, Oozeki H, Muraoka S, Tanaka S, Motegi Y, Nihei H, Yamada Y, Masuoka N and Nihei K: Synthesis and evaluation of bibenzyl glycosides as potent tyrosinase inhibitors. Eur J Med Chem 46: 1374-1381, 2011.

37. Brás NF, Gonçalves R, Mateus N, Fernandes PA, Ramos MJ and de Freitas V: Inhibition of pancreatic elastase by polyphenolic compounds. J Agric Food Chem 58: 10668-10676, 2010.

38. Lee YM, Kim YK, Kim KH, Park SJ, Kim SJ and Chung JH: A novel role for the TRPV1 channel in UV-induced matrix metalloproteinase (MMP)-1 expression in HaCaT cells. J Cell Physiol 219: 766-775, 2009.

39. Shrirasugi I, Sakakibara Y, Yamasaki M, Nishiyama K, Matsui T, Liu MC and Suiko M: Novel screening method for potential skin-whitening compounds by a luciferase reporter assay. Biosci Biotechnol Biochem 74: 2253-2258, 2010.

40. Caterina MJ, Schumacher MA, Tominaga M, Rosen TA, Levine JD and Julius D: The capsaicin receptor: A heat-activated ion channel in the pain pathway. Nature 389: 816-824, 1997.

41. Caterina MJ and Julius D: The vanilloid receptor: A molecular gateway to the pain pathway. Annu Rev Neurosci 24: 487-517, 2001.

42. Fernandes ES, Fernandes MA and Keeble JE: The functions of TRPA1 and TRPV1: moving away from sensory nerves. Br J Pharmacol 166: 510-521,2012.

43. Szallasi A and Blumberg PM: Vanilloid (capsaicin) receptors and mechanisms. Pharmacol Rev 51: 159-212, 1999.

44. Caterina MJ, Leffler A, Malmberg AB, Martin WJ, Trafton J, Petersen-zeitz KR, Koltzenburg M, Basbaum AI and Julius D: Impaired nociception and pain sensation in mice lacking the capsaicin receptor. Science 288: 306-313, 2000.

45. Keeble J, Russell F, Curtis B, Starr A, Pinter E and Brain SD Involvement of transient receptor potential vanilloid 1 in the vascular and hyperalgesic components of joint inflammation. Arthritis Rheum 52: 3248-3256, 2005.

46. Feske S, Gwack Y, Prakriya M, Srikanth S, Puppel SH, Tanasa B, Hogan PG, Lewis RS, Daly M and Rao A: A mutation in Orail causes immune deficiency by abrogating CRAC channel function. Nature 441: 179-185, 2006. 
47. Gwack Y, Srikanth S, Oh-Hora M, Hogan PG, Lamperti ED, Yamashita M, Gelinas C, Neems DS, Sasaki Y, Feske S, et al: Hair loss and defective T- and B-cell function in mice lacking ORAI1. Mol Cell Biol 28: 5209-5222, 2008.

48. Hoth M and Penner R: Depletion of intracellular calcium stores activates a calcium current in mast cells. Nature 355: 353-356, 1992.

49. Soboloff J, Spassova MA, Tang XD, Hewavitharana T, Xu W and Gill DL: ORAI1 and STIM reconstitute storeoperated calcium channel function. J Biol Chem 281: 20661-20665, 2006.

50. Feske S: ORAI1 and STIM1 deficiency in humanand mice: Roles of store-operated $\mathrm{Ca} 2+$ entry in the immune system and beyond. Immunol Rev 231: 189-209, 2009.

51. Peng MM, Fang Y, Hu W and Huang Q: The pharmacological activities of Compound Salvia Plebeia Granules on treating urinary tract infection. J Ethnopharmacol 129: 59-63, 2010.
52. Jung HJ, Song YS, Lim CJ and Park EH: Anti-inflammatory, anti-angiogenic and anti-nociceptive activities of an ethanol extract of Salvia plebeia R. Brown. J Ethnopharmacol 126: 355-360, 2009.

53. Choi JK, Oh HM, Park JH, Choi JH, Sa KH, Kang YM, Park PH, Shin TY, Rho MC and Kim SH: Salvia plebeia extract inhibits the inflammatory response in human rheumatoid synovial fibroblasts and a murine model of arthritis. Phytomedicine 15: 415-422, 2015.

54. Choi JK, Oh HM, Lee S, Kwon TK, Shin TY, Rho MC and Kim SH: Salvia plebeia suppresses atopic dermatitis-like skin lesions. Am J Chin Med 42: 967-985, 2014. 